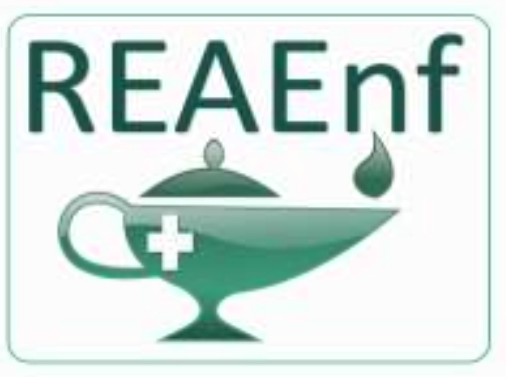

Revista Eletrônica Acervo Enfermagem
RELATO DE EXPERIÊNCIA

Recebido em: 10/2019

Aceito em: 10/2019

Publicado em: 11/2019

\title{
Relato de experiência sobre o uso de celulares e adornos em uma unidade de terapia intensiva
}

\author{
Experimental report on the use of cellphones and adornaments in a intensive care unit \\ Relato de experiencia sobre el uso de telefono celular y adornos en una unidad de \\ cuidados intensivos
}

\begin{abstract}
Gabriela Carvalho Sebastião ${ }^{1 *}$, Carla Denari Giuliani ${ }^{1}$, Bruna Aparecida Rodrigues Duarte ${ }^{1}$, Newton Ferreira de Paula Júnior ${ }^{1}$.
\end{abstract}

\begin{abstract}
Resumo: Relatar a experiência, por meio da observação, de acadêmicas de Enfermagem acerca do uso de telefone celular e adornos pelos profissionais de saúde na Unidade de Terapia Intensiva (UTI) Adulto de um hospital universitário. Estudo descritivo com base nas experiências de acadêmicas do $9^{\circ}$ período do curso de Enfermagem durante estágio realizado na UTI Adulto de um Hospital de Clínicas localizado no Triângulo Mineiro, no período de março a junho de 2019. Os profissionais de saúde muitas vezes não fazem o uso de equipamentos de proteção individual de forma adequada, como o uso de capote para manuseio de bombas de infusão e uso de touca e máscara no preparo de medicações. Além do uso frequente de celulares e adornos na unidade. Celulares e adornos são focos de disseminação de patógenos em ambiente hospitalar e o uso de equipamentos de proteção e a higienização das mãos são fundamentais para redução da contaminação.
\end{abstract}

Palavras-chave: Infecção Hospitalar, Unidades de Terapia Intensiva, Enfermagem, Telefone celular.

\begin{abstract}
To report the experience, through observation of Nursing students about the observation of cell phone use and adornments by health professionals in the Adult Intensive Care Unit (ICU) of Hospital de Clínicas in the Triângulo Mineiro. A descriptive study based on the experiences of the 9th period Nursing students during a internship at the ICU of the UFU's Hospital, from March to June 2019. Health professionals often do not the use of adequate individual protective equipment, such as the use of hospital apron for the handling of infusion pumps and the use of disposable cap and mask in the preparation of medications. In addition to frequent use of cell phones and adornaments in the unit. Cell phones and adornments are centers of dissemination of pathogens in a hospital environment, and the use of protective equipment and hand hygiene are fundamental to reduce contamination.
\end{abstract}

Keywords: Cross Infection, Intensive Care Units, Nursing, Cell Phone.

Resumen: Informar sobre la experiencia, a través de la observación de los estudiantes de enfermería sobre la observación del uso de teléfonos celulares y adornos por parte de profesionales de la salud en la Unidad de Cuidados Intensivos para Adultos ( $\mathrm{UCl}$ ) de un hospital universitario. Un estudio descriptivo basado en las experiencias de los estudiantes del 9o período del curso de Enfermería durante una pasantía en el UCl del Hospital de Clínicas localizado no Triângulo Mineiro, de marzo a junio de 2019. Los profesionales de la

${ }^{1}$ Universidade Federal de Uberlândia (UFU), Uberlândia-MG. *E-mail: gabriela enf@outlook.com 
salud a menudo no lo hacen. el uso de equipo de protección personal adecuado, como el uso de un capote para el manejo de bombas de infusión y el uso de gorro y máscara en la preparación de medicamentos. Además del uso frecuente de celulares y adornos en la unidad. Los teléfonos celulares y los adornos son centros de diseminación de patógenos en un entorno hospitalario, y el uso de equipos de protección y la higiene de las manos son fundamentales para reducir la contaminación.

Palabras clave: Infección Hospitalaria, Unidades de Cuidados Intensivos, Enfermería, Teléfono Celular.

\section{INTRODUÇÃO}

A melhora do estado de saúde do paciente está diretamente relacionada a assistência prestada pela equipe de saúde. Atualmente, um dos grandes desafios é a diminuição das taxas das Infecções Relacionadas à Assistência à Saúde (IRAS) que impactam no aumento dos custos do cuidado, tempo de internação e piora do quadro clínico (BRASIL, 2017; SECRETARIA DE SAÚDE, 2017).

As IRAS são definidas como qualquer infecção relacionada a procedimentos hospitalares que se manifestam durante a internação ou após a alta do paciente. Sua ocorrência se deve principalmente à má realização de técnicas assépticas que reflete na contaminação de procedimento invasivos, dos dispositivos de assistência, feridas cirúrgicas, entre outros (SILVA RE, 2018).

Um recurso importante no combate das infecções hospitalares (IH) é a higienização das mãos. Essa simples ação diminui a transmissão cruzada de microrganismos e a contaminação de equipamentos, contribuindo para salvar vidas e reduzir significativamente o número de IRAS. O uso correto de Equipamentos de Proteção Individual (EPIs) aliado a prática de higiene é uma grande responsabilidade, principalmente da equipe de enfermagem, por estar em contato constante com o paciente e por estar mais exposta aos materiais biológicos (KILPATRICK C, 2019; JORDÃO S, 2019).

A disseminação de patógenos é um desafio, em especial nos últimos anos com o aumento do uso e da popularidade de objetos como telefones celulares. O celular é uma fonte de contaminação por entrar em contato direto com as mãos do profissional de saúde, além de nariz, boca e orelha, e estes são dificilmente desinfectados. Os adornos também constituem uma preocupação aos órgãos de saúde por serem objetos potencialmente transmissores de microrganismos. Segundo a Norma Regulamentadora 32 (NR 32), do Ministério do Trabalho "no ambiente de trabalho com possível exposição a agente biológico, [...] é estritamente proibido usar adornos (por exemplo: alianças e anéis, pulseiras, relógios de uso pessoal, colares, brincos, [...])" (SÃO PAULO, 2014; SOUZA LLB, 2018).

A Unidade de Terapia Intensiva (UTI) é o setor que possui maior incidência de IRAS devido à gravidade do estado de saúde dos pacientes e o maior número de procedimentos invasivos. Devido a importância do tema para a área da saúde, o Governo Federal dispõe da Lei 9.431/1997 que trata da prevenção e controle de infecção em ambiente hospitalar determinando protocolos de desinfecção, medidas de precaução, higienização das mãos, etc (BRASIL, 2019; JORDÃO S, 2019).

Dessa forma, o presente trabalho tem como objetivo relatar a experiência de acadêmicas do 9 ำ período do curso de Enfermagem da Universidade Federal de Uberlândia sobre a observação do uso de telefone celular e adornos em profissionais de saúde na UTI Adulto de um hospital universitário.

\section{RELATO DE EXPERIÊNCIA}

Estudo descritivo do tipo relato de experiência com suporte na revisão da literatura e com base na vivência das alunas do 9o período do curso de Graduação em Enfermagem durante o estágio supervisionado obrigatório, realizado na Unidade de Terapia Intensiva Adulta de um Hospital Universitário de grande porte localizado no Triângulo Mineiro, no período de março a junho de 2019.

O estágio supervisionado possui uma carga horária total de 465 horas, tendo como objetivo a inserção do acadêmico no ambiente hospitalar. Durante o estágio foram realizadas atividades específicas da 
profissão do enfermeiro, como por exemplo, cateterismo vesical; prescrição de enfermagem; preparo e administração de medicamentos; atividades gerenciais; educação em saúde; capacitações com a equipe; observação do funcionamento do setor e realização de intervenções que visem a melhoria do serviço.

Ao longo do estágio na UTI, foi observado pelas alunas que os profissionais muitas vezes não fazem o uso de EPI's de forma adequada e nos momentos necessários. Em situações de precaução de contato por exemplo, foi notado que muitos profissionais não fazem o uso de capote para manuseio de bombas de infusão e instalação de dietoterapia e não fazem o uso da máscara no preparo de medicações.

Com relação ao ambiente extra-hospitalar, foi observado pelas estagiárias o uso dos EPl's indevidamente, sendo o jaleco o principal utilizado. Ressaltando que a Norma Regulamentadora NR-32 da Agência Nacional de Vigilância Sanitária (ANVISA) restringe o uso do jaleco fora do local de suas atividades laborais, a Central de Controle de Infecção Hospitalar $(\mathrm{CClH})$ insere o não uso em suas recomendações, além da Lei 21.450 de 2014 sancionada em Minas Gerais proibindo o uso do jaleco fora do hospital, ainda há o uso por muitos profissionais em outros estabelecimentos, como, restaurantes, lanchonetes e transporte público.

$\mathrm{Na}$ unidade vivenciada as acadêmicas de enfermagem presenciaram diversas vezes as discussões em reuniões e capacitações com a equipe de profissionais sobre o uso do jaleco fora do ambiente de trabalho aumentar o índice de infecção hospitalar, devido a comprovações em muitos estudos que o "jaleco", "avental" e "roupa hospitalar" são porta de entrada para aglomeração de bactérias e vírus, sendo responsáveis por muitas patologias que agravam o estado clínico dos pacientes, podendo evoluir para óbito. Porém, não foi possível observar mudanças em relação ao comportamento dos mesmos.

A correta técnica na lavagem das mãos é de suma importância no serviço de saúde, porém foi observado que os profissionais da UTI não executam a técnica correta ou não realizam a higienização das mãos.

Ficando evidente ainda que em grande parte do tempo em que estão no setor preferem utilizar o álcool em gel, sabendo que é necessário intercalar a lavagem com o uso do álcool, não podendo a higienização das mãos ser substituída pelo antisséptico em gel.

Nesse contexto de prática vivenciado, é recorrente o uso de celulares e adornos, como anéis e brincos; as estagiárias presenciaram vários momentos em que os profissionais iam realizar procedimentos e não retiravam seus adornos e faziam uso de celular, seja dentro ou fora dos leitos. Além de que em nenhum momento foi presenciado a limpeza dos celulares ou adornos durante o estágio.

O uso de EPI's e a higienização das mãos de forma adequada reduzem risco de contaminação e disseminação de patógenos no meio hospitalar, sendo seu uso indispensável para profissionais da saúde, principalmente nas UTI's onde os pacientes são submetidos a procedimentos invasivos e são manipulados várias vezes ao dia.

\section{DISCUSSÃO}

A saúde pública tem como um agravante crítico a transmissão de agentes infecciosos. No entanto, existe um conjunto de medidas que são utilizadas como forma eficiente para reduzir os riscos de infecção, que são as medidas de precaução-padrão, que inclui a higienização das mãos, uso adequado dos EPIs e de proteção coletiva, imunização e manuseio correto de resíduos dos serviços de saúde (SOUSA FF, SOUSA IA, OLIVEIRA LMN, 2019).

Os dispositivos utilizados pelos profissionais da saúde, denominados EPIs, são essenciais para realizar a prestação de cuidados à saúde com segurança, para prevenir os riscos que estão expostos diariamente. Os EPIs mais usados são: toucas, óculos, protetor auricular, luvas de procedimento, capote descartável e calçados fechados (CAVALCANTE LL, PRADO RMS, 2018). 
Um estudo realizado em Januária-MG avaliou a tela de aparelhos celulares, constatou que de acordo com o padrão da American Public Health Association (APHA) $75 \%$ das amostras coletadas apresentavam contaminação superior de bactérias mesófilas aerofílicas, bolores e leveduras. Mostra ainda que todos os ambientes estão susceptíveis a contaminação por microrganismos, sendo diretamente relacionado com a higiene do local, dessa forma, os objetos que entram em contato com várias pessoas ou locais podem aumentar a chance de contaminação e infecção (SOUZA LLB, FERREIRA LC, 2018).

Em um outro estudo concretizado em Teresópolis-RJ foi comprovado que existe uma colonização predominante de cocos Gram positivos em jalecos brancos que foi realizado por análises microbiológicas. A espécie mais comum que foram analisadas no bolso e punho era de Staphylococcus spp, seguido de Bacilos Gram negativos e Bacilos Gram positivos. Os jalecos além de serem fontes de infecção cruzada, são fontes de agentes patogênicos. Sendo um importante elo na cadeia epidemiológica, como na prevenção, quanto na transmissão de Infecções Relacionadas à Assistência à Saúde e, deste modo, deve ser repensado a forma de ser usado e deve ser estimulado a adoção de práticas de segurança para minimizar os riscos e provocar o raciocínio preventivo desde a formação acadêmica (SCHEIDT KLS, et al., 2015).

Portanto é de suma importância que os profissionais sejam sensibilizados a respeito da utilização correta das vestimentas hospitalares e sua manipulação após ser utilizado, porém de outras normas de biossegurança também, como por exemplo a da higienização das mãos. Contudo também é indispensável incluir em todos os níveis do processo de formação dos futuros profissionais de saúde, em relação a essa temática, o quanto é necessário e relevante, pois esses profissionais são os principais participantes do processo de prevenção de transmissão de infecção (SILVA TML, et al., 2019).

De acordo com a Organização Mundial de Saúde (OMS), a transmissão de microrganismos resistentes por meio das mãos dos profissionais da saúde, de paciente para paciente, é uma ocorrência comum, principalmente nos hospitais. A principal medida para se pensar em redução de infecções hospitalares é a correta execução do processo de higienização das mãos (SILVA RE, et al., 2018).

Mediante a esses resultados, fica evidente a necessidade da orientação aos profissionais de saúde para adoção de medidas preventivas com relação à infecção cruzada. Algumas estratégias viáveis para 0 controle das infecções incluem a correta lavagem das mãos, uso de luvas, cuidados com dejetos e secreções, desinfecção de objetos que entrem em contato com várias pessoas e superfícies, dentre outras. A implantação dessas medidas contribui não só para redução do índice de infecção, mas também reduzem gastos envolvidos com o cuidado ao paciente contaminado e/ou infectado (STUCHI RAG, et al., 2013; REIS LE, et al., 2015).

\section{CONSIDERAÇÕES FINAIS}

Celulares e adornos são responsáveis por contaminação cruzada quando não há a realização da técnica correta da higienização das mãos e limpeza com produtos adequados após serem utilizados no ambiente hospitalar. A partir da observação do frequente uso desses objetos no local descrito, foi planejado uma capacitação sobre Infecção em Ambiente Hospitalar com foco em higienização das mãos, uso de telefones celulares e adornos na UTI do Hospital de Clínicas da Universidade Federal de Uberlândia para orientação e atualização dos profissionais de saúde. Após a capacitação, o uso desses objetos foi proibido nas áreas de assistência, sendo permitido apenas nos locais de lazer. A adesão ocorrerá de forma gradativa até o assentimento total da unidade.

\section{AGRADECIMENTOS}

Este trabalho só foi possível mediante colaboração das acadêmicas do Curso de Graduação em Enfermagem da Universidade Federal de Uberlândia, Fernanda Miranda de Sena; Isabela Naiala Martins de Moraes; Isabele Eufrásio de Brito, e principalmente minhas queridas amigas e colegas de profissão Bruna Cristina, Dayane Lima, Stéfane Justino, Oridia Carollynne, Isadora Sanitá, Ana Paula Souza e Andressa Célio que sempre me ajudaram e acreditaram em mim. 


\section{REFERÊNCIAS}

1. BRASIL. 2017. In: ANVISA (Agência Nacional de Vigilância Sanitária). Caderno 4: Medidas de Prevenção de Infecção Relacionada à Assistência à Saúde. Brasília.

2. Cavalcante LL, Prado RMS. Utilização de EPIs por profissionais da saúde em ambiente hospitalar. In: Mostra Científica da Farmácia; maio 2018. Quixadá, Ceará. v. 4 n. 2.

3. JORDÃO S, NASCIMENTO JC. Crescimento Microbiológico nos Adornos dos Profissionais de Saúde na UTI. Revista Pró-UniverSUS, 2018; 09(2):11-13.

4. KILPATRICK C, et al. Sounds easy, but not when it comes to implementation, Suiça. Journal of Infection and Public Health, 2019; 12: 301-303.

5. PARANÁ. SECRETARIA DE SAÚDE. In: Entenda o que é Infecção Hospitalar. Curitiba.

6. SÃO PAULO. Secretaria de Saúde. Cartilha 13: Normas Regulamentadoras no 7, no 9 e n 32 . São Paulo: Governo do Estado de São Paulo; 2014.

7. SCHEIDT KLS, et al. Práticas de utilização e perfil de contaminação microbiológica de jalecos em escola médica. Revista Medicina (Ribeirão Preto, On-line), 2015; 48(5): 467-77.

8. SILVA RE, et al. Conhecimento de Estudantes da Área da Saúde Sobre o Controle e Prevenção de Infecções Hospitalares. Revista Brasileira de Ciências da Saúde, 2018; 22(2): 131-138.

9. SILVA TML, et al. Vestimentas dos profissionais da saúde: riscos e cuidados necessários. Revista de Administração em Saúde, 2019; 19(74): 1-16.

10. SOUSA FF, et al. A utilização de equipamentos de proteção individual e coletiva por profissionais de saúde: revisão integrativa. Revista de Atenção à Saúde, 2019; 16(58): 102-108.

11. SOUZA LLB, FERREIRA LC. Contaminação microbiológica em Smartphones. Revista Vértices, 2018; 20(2): 207212.

12. STUCHI RAG, et al. Contaminação bacteriana e fúngica dos telefones celulares da equipe de saúde num hospital em minas gerais. Revista Ciência, Cuidado e Saúde, 2013; 12(4): 760-767.

13. REIS LE, et al. Contaminação de telefones celulares da equipe multiprofissional em uma unidade de terapia intensiva. Revista eletrônica Saber Digital, 2015; 8(1): 68-83. 